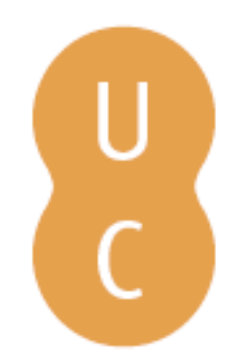

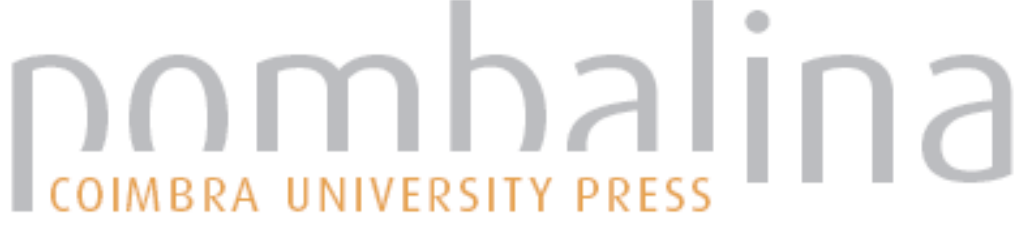

\section{O Arquivo LdoD e a Biblioteca Digital}
Autor(es):
Portela, Manuel
Publicado por: Imprensa da Universidade de Coimbra
URL
persistente:
URI:http://hdl.handle.net/10316.2/36985
DOI:
DOI:http://dx.doi.org/10.14195/978-989-26-1045-0_14

Accessed : $\quad$ 26-Apr-2023 11:55:47

A navegação consulta e descarregamento dos títulos inseridos nas Bibliotecas Digitais UC Digitalis, UC Pombalina e UC Impactum, pressupõem a aceitação plena e sem reservas dos Termos e Condições de Uso destas Bibliotecas Digitais, disponíveis em https://digitalis.uc.pt/pt-pt/termos.

Conforme exposto nos referidos Termos e Condições de Uso, o descarregamento de títulos de acesso restrito requer uma licença válida de autorização devendo o utilizador aceder ao(s) documento(s) a partir de um endereço de IP da instituição detentora da supramencionada licença.

Ao utilizador é apenas permitido o descarregamento para uso pessoal, pelo que o emprego do(s) título(s) descarregado(s) para outro fim, designadamente comercial, carece de autorização do respetivo autor ou editor da obra.

Na medida em que todas as obras da UC Digitalis se encontram protegidas pelo Código do Direito de Autor e Direitos Conexos e demais legislação aplicável, toda a cópia, parcial ou total, deste documento, nos casos em que é legalmente admitida, deverá conter ou fazer-se acompanhar por este aviso.

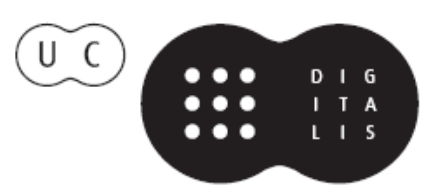



Tendo como pano de fundo as Comemorações dos seus 500 anos, a Biblioteca Geral da Universidade de Coimbra organizou um Congresso Internacional subordinado ao tema "A Biblioteca da Universidade: permanência e metamorfoses", que teve lugar nos dias 16, 17 e 18 de janeiro de 2014, no auditório da Reitoria da Universidade de Coimbra.

O objetivo maior desta reunião científica foi o de refletir sobre o presente e o futuro das bibliotecas que servem públicos universitários. Numa outra vertente, procurou chamar-se a atenção para a importância de que a Biblioteca se reveste, tendo em vista o progresso do conhecimento técnico e científico. Por último, o Congresso pretendeu instituir-se como oportunidade de reflexão prospetiva e como lugar de encontro entre as sensibilidades de todos os que trabalham profissionalmente com livros e com outros suportes de natureza bibliográfica.

Nesse sentido, foram apresentadas Conferências, Mesas Redondas e sessões de Testemunhos em torno de temas como o valor das bibliotecas universitárias, a biblioteca universitária em contexto; as mudanças e os desafios; a biblioteca universitária e a sociedade da informação e conhecimento; o impacto do acesso aberto na comunidade científica, e as bibliotecas digitais. 


\title{
MANUEL PORTELA
}

Universidade de Coimbra

University of Coimbra

\section{O ARQUIVOLDOD EA BIBLIOTECA DIGITAL}

\author{
The LDOD ARChive AND THE Digital LibRary
}

RESUMO: O arquivo digital dedicado ao Livro do Desassossego (LdoD) de Bernardo Soares/Fernando Pessoa agregará fac-símiles de documentos autógrafos e transcrições textuais correspondentes a diferentes edições impressas da obra, propondo um modelo dinâmico de interação entre os leitores e o conjunto de remediações textuais ${ }^{1}$. Enquanto meta-edição de um conjunto de documentos autorais e de livros que editam e organizam esses documentos, o Arquivo LdoD possibilita reconfigurações variáveis dos elementos textuais e bibliográficos de modo a tirar partido da processabilidade do meio digital. Uma breve análise da natureza dinâmica deste arquivo (ao nível das funcionalidades de edição e escrita) é usada para interrogar o conceito de biblioteca digital.

Palavras-chave: Biblioteca Digital; Arquivo Digital; Web 2.0; Materialidade Digital; Livro do Desassossego; Fernando Pessoa.

ABSTRACT: The digital archive dedicated to the Book of Disquiet (LdoD) by Bernardo Soares/Fernando Pessoa will aggregate facsimiles of autograph documents and textual transcriptions of different printed editions of the work. This archive embodies a dynamic model of interaction between readers and a large corpus of textual remediations. Considered as a meta-edition of both a set of authorial documents and a series of books in which those documents have been edited and organized, the LdoD Archive allows for variable reconfigurations of textual and bibliographical elements, taking advantage of the processability of the digital medium. A brief analysis of the dynamic nature of this archive (at the level of its editing and writing features) is used for interrogating the concept of digital library.

Keywords: Digital library; Digital archive; Web 2.0; Digital materiality; Livro do Desassossego; Fernando Pessoa.

1 "Nenhum problema tem solução: um arquivo digital do Livro do Desassossego" (PTDC/ CLE-LLI/118713/2010, investigador principal: Manuel Portela), projeto financiado pela FCT e cofinanciado pelo FEDER, através do Eixo I do Programa Operacional Fatores de Competitividade (POFC) do QREN, COMPETE: FCOMP-01-0124-FEDER-019715. 


\section{Introdução}

A biblioteca digital é geralmente imaginada a partir da remediação do acervo bibliográfico manuscrito e impresso e dos metadados que permitem pesquisar, localizar e apresentar as versões digitais desse acervo. Se uma parte da estrutura e funções da biblioteca digital do presente e do futuro resulta da transcodificação maciça do património escrito e dos média analógicos para formatos digitais, uma outra parte, proporcionalmente maior à medida que a produção documental digital se incrementa, resultará da preservação, organização e classificação de objetos originariamente digitais. Estes objetos obedecem a processos de produção de unidades documentais semelhantes aos que foram herdados das tecnologias anteriores, mas são ao mesmo tempo determinados pelos formatos de ficheiro e protocolos de publicação característicos da internet.

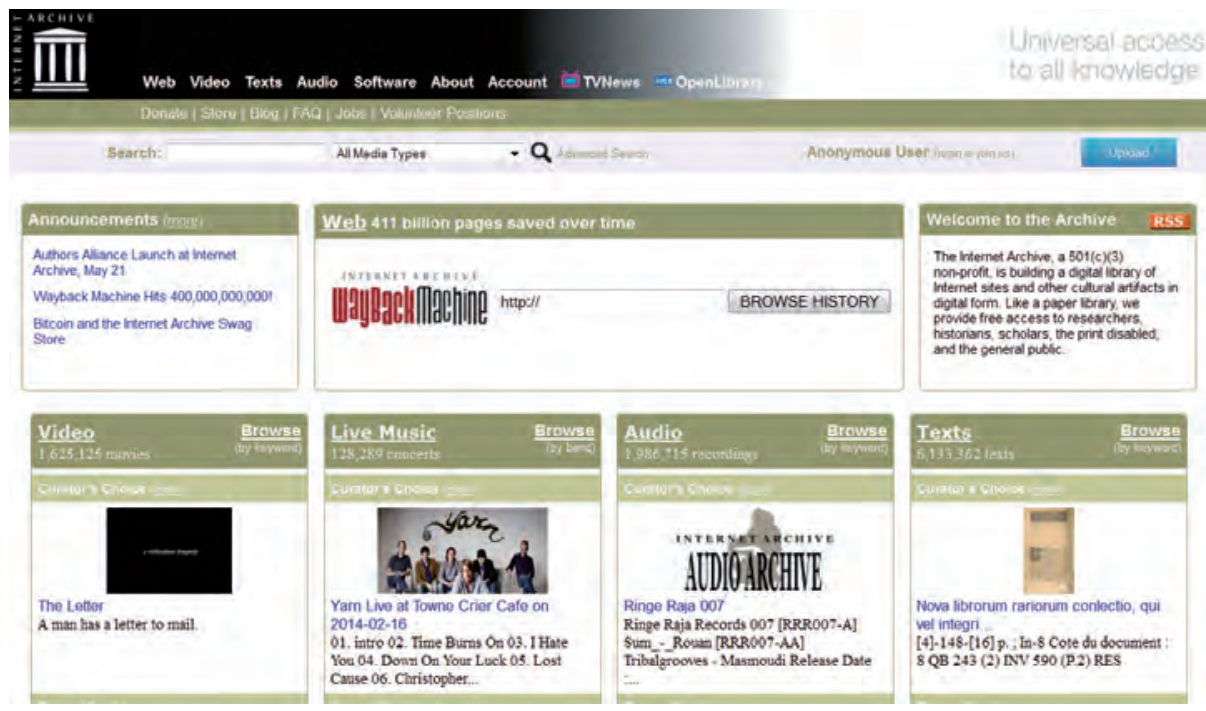

FIGURA 1. Página de entrada do Internet Archive

(captura de ecrã realizada a 20 de maio de 2014): https://archive.org/index.php

Autodescrevendo-se, no dia 20 de maio de 2014, como "a non-profit digital library offering free universal access to books, movies \& music, 
as well as 411 billion archived web pages", o Internet $\operatorname{Archive}^{2}$ propõe, de certo modo, outro conceito de biblioteca digital: o da própria internet como uma espécie de biblioteca universal, alimentada pelo desejo de fazer coincidir toda a informação existente com toda a informação colecionada (Figura 1). Este desejo decorre da ubiquidade dos dispositivos de registo de textos, sons e imagens (incluindo imagens em movimento) e da capacidade de armazenamento dos suportes digitais, que exponenciaram as nossas práticas quotidianas de gerar inscrições e, portanto, documentos suscetíveis de serem colecionados e classificados como itens em bibliotecas e em arquivos.

Neste artigo interrogo brevemente a própria noção de biblioteca digital a partir de três características fundamentais da informação digital: a possibilidade de reconfiguração contínua do ficheiro de dados que constitui um objeto digital, com a consequente instabilidade textual e medial; a variabilidade crescente da modularidade documental à medida que o software dos média favorece a hibridização de géneros e formas por efeito da recombinação das técnicas de manipulação de objetos digitais, desafiando as taxonomias usadas nos esquemas de metadados para classificar esses objetos; e, por fim, a natureza dinâmica e colaborativa dos espaços de informação eletrónica, baseados na manipulação e na produção aberta e partilhada de múltiplas versões dos objetos digitais.

Sugiro que a edição digital, quando pensada como o universo de objetos digitais publicados no espaço público eletrónico, desafia os processos de coleção e classificação de documentos herdados das tecnologias e média analógicos, a partir dos quais as noções de biblioteca e mediateca se construíram. Por outras palavras: é possível uma biblioteca digital de objetos digitais cujas modularidades não coincidam com as modularidades dos sistemas classificatórios das ciências bibliográficas? O que acontece se tentarmos pensar a biblioteca digital para além do modelo da remediação virtual da biblioteca? Por exemplo, o que seria o Internet Archive nessa biblioteca digital? E os itens preservados no Internet Archive? Seria

2 The InTERnet ARChIVE. San Francisco, 1996-2014. [Consult. 6 mai. 2014]. Disponível na WWW em: <URL: https://archive.org/index.php>. 
a biblioteca digital um item no arquivo da internet? Ou seria o arquivo da internet um item na biblioteca digital? O que acontece quando a própria biblioteca perde a modularidade que a define e o seu conteúdo pode transformar-se continuamente por efeito da manipulação dos utilizadores? Será essa a consequência última do hipertexto eletrónico? A dissolução das fronteiras concetuais que permitem ligar um corpus de textos e objetos mediais a uma prática classificatória específica?

\section{Noções de biblioteca digital}

A hibridez categorial e formal dos objetos digitais, resultante do processo geral de softwarização da cultura e do seu património documental a partir de um conjunto de técnicas partilhadas por diferentes aplicações informáticas, tem implicações categoriais relativas à tipologia documental e aos géneros e formas. Tal como afirma Lev Manovich, uma parte significativa das propriedades dos objetos digitais depende da camada do software:

Strictly speaking, while it is certainly convenient to talk about properties of websites, digital images, 3D models, GIS representations, etc., it is not accurate. Different types of digital content do not have any properties by themselves. What as users we experience as properties of media content comes from software used to create, edit, present, and access this content. ${ }^{3}$ (itálicos no original)

Isto pode observar-se, por exemplo, num género eletrónico como o 'weblog' (ou 'blog'), cujas propriedades digitais são determinadas pelas funcionalidades programadas na plataforma de criação, edição e publicação, muitas das quais são comuns a outras aplicações de software como acontece com as funções de edição de texto e imagem oferecidas aos autores ou com as funções de comentário, republicação e partilha

3 MANOVICH, Lev - Software takes command: extending the language of new media. London: Bloomsbury, 2013. p. 150. 
oferecidas aos leitores. Assim, para além das propriedades materiais e estilísticas resultantes da integração multimedial de texto, imagem, áudio e vídeo, as propriedades do objeto digital 'blog' dependem dessa camada de código que lhe conferem a editabilidade e manipulabilidade específica da sua forma, a qual varia ainda consoante as alterações tecnológicas de sucessivas versões do software.

Por seu turno, a transferência da noção de biblioteca para o espaço eletrónico em rede implica a sua consequente reconfiguração concetual, seja como justificação para recriar numa determinada estrutura de base de dados a estrutura e as funções da biblioteca física, seja no sentido de entender o espaço eletrónico no seu todo como um novo tipo de instanciação material e técnica da biblioteca. Por outro lado, a obsolescência dos formatos e protocolos digitais origina um conjunto de dilemas epistemológicos nos processos de construção da biblioteca digital de objetos digitais, como acontece, por exemplo, no caso da literatura digital ${ }^{4}$. Se na década de 1990 ainda era possível imaginar a biblioteca digital a partir da simples migração da biblioteca de papel para as redes digitais, a explosão dos média sociais e das possibilidades de interação na web 2.0 nos inícios do século XXI, alterou a própria concetualização de biblioteca digital. Com efeito, as diversas aceções da expressão 'biblioteca digital' refletem as rápidas mudanças tecno-sociais nos processos de produção, indexação, pesquisa e distribuição da informação em rede:

The term 'Digital Library' is currently used to refer to systems that are very different in scope and yield very diverse functionality. These systems range from digital object and metadata repositories, reference-linking systems, archives, and content administration systems, which have been mainly developed by industry, to complex systems that integrate advanced digital library services, which have chiefly been developed in research environments. 5

4 NAMORA, Ricardo - El concepto de biblioteca digital como cuestión epistemológica. GARRIDO GALLARDO, Miguel Ángel, ed. - La biblioteca de Occidente en contexto bispánico. Logroño: Universidad Internacional de La Rioja, 2013. p. 73-84.

5 CANDEla, L. [et al.] - Digital library manifesto. [Em linha]. DL.org Consortium. 2011a. [Consult. 26 Mai. 2014]. Disponível na WWW em: <URL: http://www.dlorg.eu>. 
Nesta heterogeneidade de sistemas e referências parecem confluir uma redefinição técnica e uma redefinição metafórica da biblioteca. Assim, a reconstituição de um conjunto de funções de preservação documental e de agregação e recuperação da informação no espaço digital pode referir quer uma rede fechada de objetos digitais, sujeitos a diversos tipos de validação institucional, quer uma rede aberta e dispersa de objetos digitais, independentes de validação institucional. Esta distribuição aberta em rede de diferentes coleções de objetos de informação gera, potencialmente, um repositório universal de conhecimento que não coincide com os modos institucionais de validação e catalogação, sejam eles privados ou públicos. A biblioteca digital emergiria também como um modo particular de intervenção técnica e social nesse espaço aberto de publicação e comunicação.

Ao mesmo tempo, a acelerada digitalização do património e da produção cultural conduz à reinvenção dos próprios modelos de biblioteca digital em sentido estrito, que passam de um sistema centrado nos conteúdos, focado na organização e no acesso estruturado às coleções de dados, para um sistema centrado no utilizador e nas experiências de interação com essas coleções:

Its main role has shifted from static storage and retrieval of information to facilitation of communication, collaboration and other forms of interaction among scientists, researchers or the general public on themes of relevance to the information stored in the Digital Library. Finally, it has moved from handling mostly centrally located text to combining distributed multimedia document collections, sensor data, mobile information and pervasive computing services. 6

A transformação do espaço eletrónico num espaço de manipulação e colaboração implicaria, portanto, a passagem de um modelo centrado na catalogação de conteúdos para um modelo centrado na flexibilidade de

${ }^{6}$ CAndela, L. [et al.] - Digital library manifesto. DL.org Consortium, 2011a. p. 4. 
interações, que incorpora o próprio dinamismo da web 2.0 nas funcionalidades de pesquisa, recuperação e socialização da informação.

Um dos resultados de um projeto recente de investigação sobre modelos de biblioteca digital aponta justamente no sentido da redefinição da biblioteca digital como um espaço de informação habitado por uma comunidade de utilizadores que cooperam e interagem nesse espaço ${ }^{7}$. A visualização de informação no seu contexto de uso e a representação dos próprios utilizadores nesse espaço cooperativo materializam este modelo de biblioteca informado pelos princípios da cooperação assistida por computador. No fundo, trata-se de importar para o modelo da biblioteca digital aquelas que são as interações caraterísticas da internet nas suas formas dinâmicas atuais. A representação integrada das múltiplas perspetivas inerentes a este modelo levou os autores $\operatorname{citados}^{8}$ a proporem uma teoria geral da biblioteca digital composta por três níveis - Biblioteca Digital, Sistema da Biblioteca Digital e Sistema de Gestão da Biblioteca Digital - definidos deste modo:

\section{Digital Library (DL)}

A potentially virtual organisation, which comprehensively collects, manages and preserves for the long term rich digital content, offering its targeted user communities specialised functionality on that content, of defined quality and according to comprehensive codified policies.

\section{Digital Library System (DLS)}

A deployed software system underpinned by a possibly distributed architecture providing all the facilities required by a specific Digital Library. Users interact with a Digital Library through the corresponding Digital Library System.

7 Desenvolvido entre 2008 e 2010 pelo DL-org Consortium (Conselho Nacional de Investigação de Itália, Universidade de Atenas e Universidade de Glasgow) e financiado pela União Europeia, o projeto 'Digital Library Interoperability, Best Practices and Modelling Foundations' resultou num conjunto de documentos que concetualizam este modelo de biblioteca digital (cf. Candela [et al.], 2011a e 2011b).

8 CANDELA, L. [et al.] - Digital library reference model: in a nutshell. [Em linha]. DL.org Consortium. 2011b. [[Consult. 26 Mai. 2014]. Disponível na WWW em: <URL:http://www. dlorg.eu>. 


\section{Digital Library Management System (DLMS)}

A generic software system which provides the appropriate software infrastructure both to produce and administer a Digital Library System incorporating the suite of facilities considered fundamental for Digital Libraries and to integrate additional software offering more refined, specialised or advanced facilities. 9

O que é interessante nesta definição, se tentarmos pensar a relação entre um arquivo digital como o Arquivo LdoD e a própria web como espaço colaborativo, é o facto de a biblioteca digital continuar a ser representada como um ato de coleção, gestão e conservação de objetos digitais, dependente de um conjunto explícito de padrões de qualidade e de funcionalidades, mesmo que a entidade organizacional responsável pela política de seleção seja potencialmente virtual. Além disso, o modelo tripartido da relação entre os sistemas de software de gestão da biblioteca digital e os sistemas de software da biblioteca digital, por um lado, e os objetos digitais, por outro, concetualiza relações similares às de quaisquer outros sistemas de informação digital. A especificidade da biblioteca digital não estaria tanto na arquitetura de software e no sistema de informação enquanto tais, mas sim nas especificações e conteúdos dos próprios objetos digitais e nas funcionalidades definidas para as suas comunidades de utilizadores.

Esta formalização tripartida pode ser testada em diferentes modelos de biblioteca digital atuais, que mostram configurações variáveis de política de coleção e produção de objetos digitais, de funcionalidades de interação com os objetos das suas coleções e de relação entre espaço institucional e espaço virtual. As possibilidades de agregação de objetos digitais - obtidos a partir da digitalização de múltiplas coleções de várias instituições (bibliotecas, arquivos e museus) - e o acesso integrado a esses objetos a partir de uma mesma interface decorrem da natureza reticular da informação digital, do desenvolvimento de protocolos abertos de interoperabilidade e de uma política de digitalização e acesso

\footnotetext{
9 CANDela, L. [et al.] - Digital library manifesto. DL.org Consortium, 2011a. p. 5-6.
} 
público ao património arquivado. Portais como os da Biblioteca Nacional Digital $^{10}$, da Europeana ${ }^{11}$, e da Digital Public Library of America ${ }^{12}$, por exemplo, constituem aplicações diferenciadas daqueles princípios

(Figuras 2, 3 e 4).

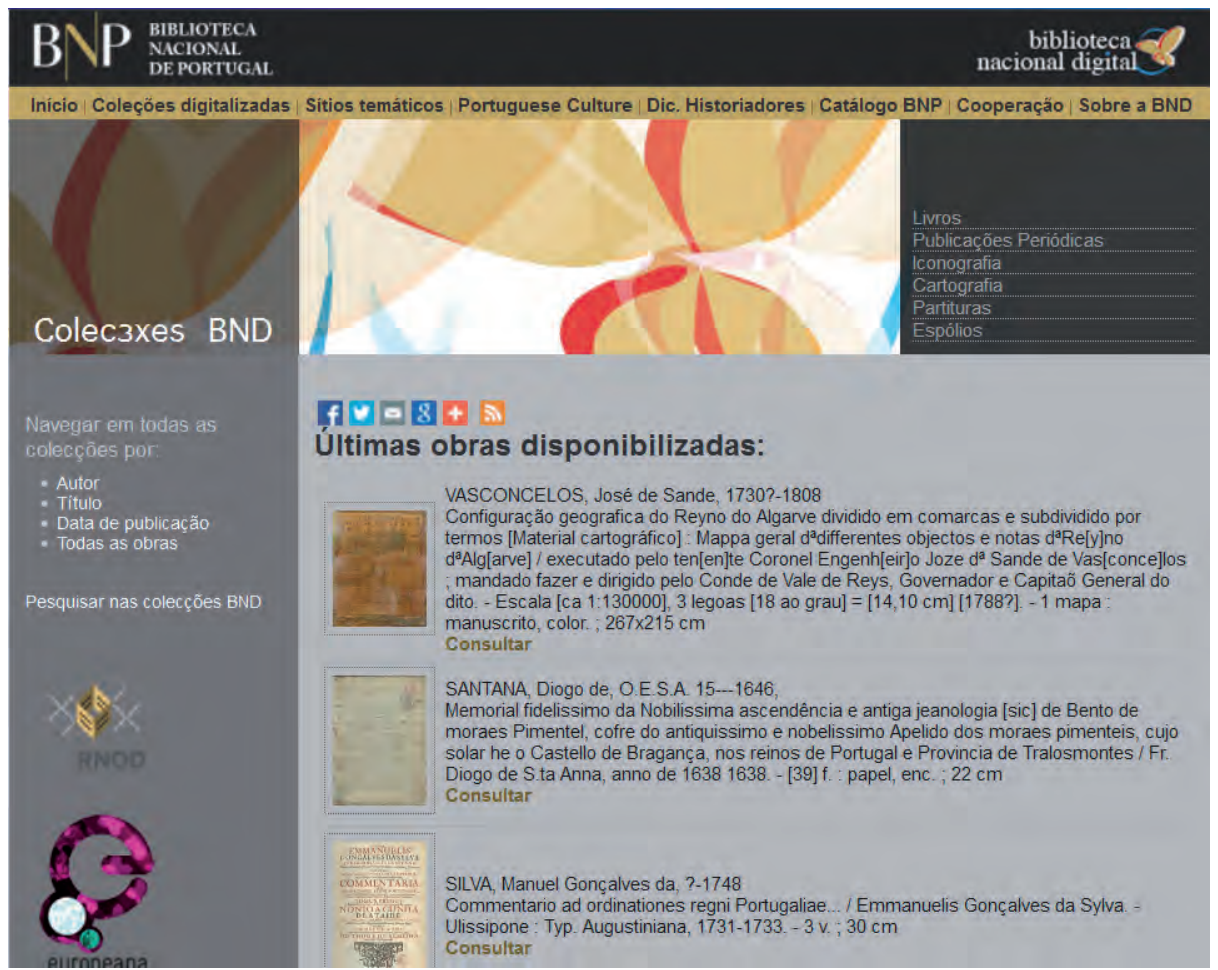

FIGURA 2. Página de entrada da Biblioteca Nacional Digital (captura de ecrã realizada a 18 de maio de 2014): http://purl.pt/index/geral/PT/index.html

10 Biblioteca Nacional De PORTUGal - Biblioteca nacional digital. Lisboa: BNP, 2002. [Consult. 26 Mai. 2014]. Disponível na WWW em: <URL:http://purl.pt/index/geral/ $\mathrm{PT} /$ index.html>.

11 THE EUROPEANA FOUNDATION - Europeana. The Hague: National Library of the Netherlands, 2008-2014. [Consult. 26 Mai. 2014]. Disponível na WWW em: <URL:http:// www.europeana.eu>.

12 Digital Public Library of America. Boston: Boston Public Library, 2013-2014. [Consult. 26 Mai. 2014]. Disponível na WWW em: <URL:http://dp.la>. 


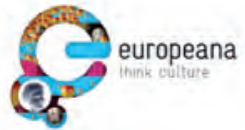

Search $\sim$

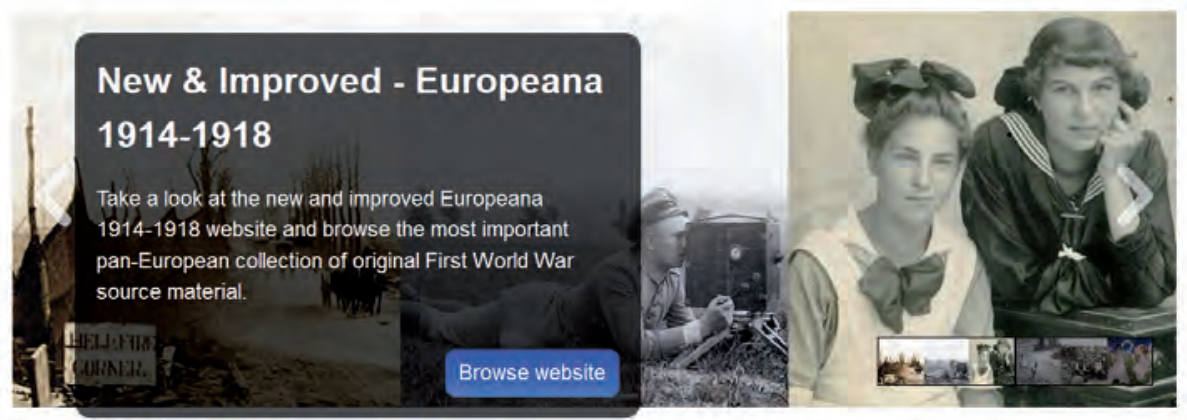

From the bloa ه

FIGURA 3. Página de entrada da Europeana (captura de ecrã realizada a 18 de maio de 2014): http://www.europeana.eu/

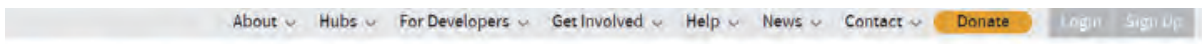

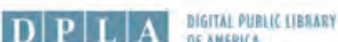
OF AMERICA

Home Exhibitions Map Timeline Bookshelf Apps
}
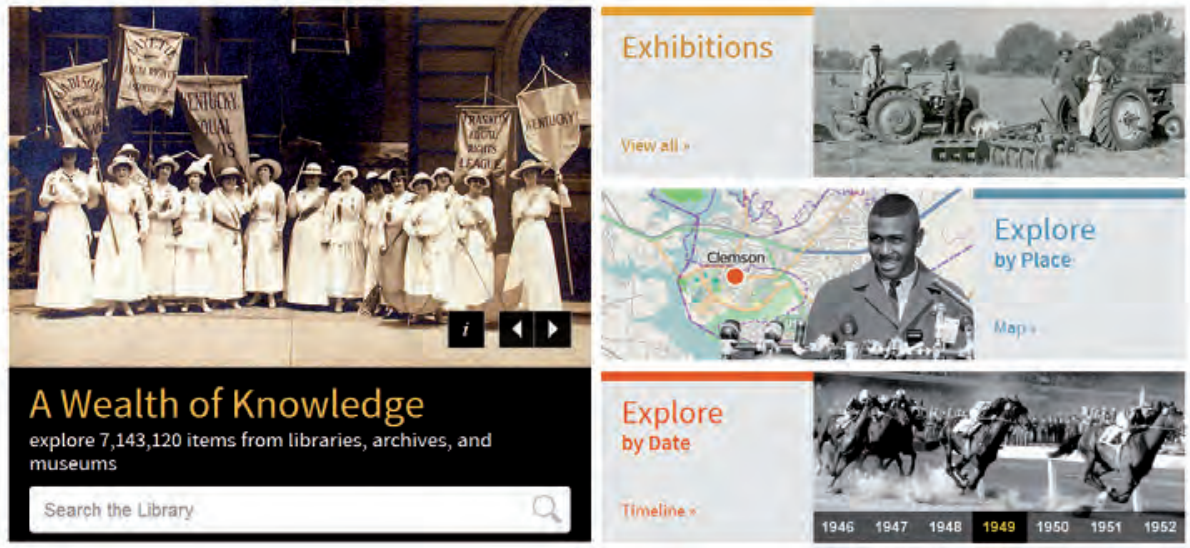

FIGURA 4. Página de entrada da Digital Public Library of America (captura de ecrã realizada a 18 de maio de 2014): http://dp.la/

A digitalização e a distribuição em rede permitem a agregação das versões digitais dos objetos para além dos limites geográficos e institu- 
cionais dos originais, exponenciando os efeitos de descontextualização, recontextualização e apropriação criativa decorrentes da reprodutibilidade técnica. São evidentes as possibilidades de socialização e apropriação através da recirculação, manipulação e recombinação de objetos digitais, seja através de funcionalidades presentes nas próprias plataformas - como os botões de partilha em redes sociais -, seja através da importação para análise e reutilização por meio de ferramentas próprias. No entanto, o facto de a biblioteca digital se constituir predominantemente a partir de objetos originariamente não-digitais, validados pelos sistemas institucionais que colecionaram e catalogaram esses objetos, parece ainda preso à metáfora da biblioteca digital dependente das fronteiras institucionais, como se a identidade dos objetos digitais enquanto itens bibliotecáveis resultasse necessariamente dessa inscrição tecno-institucional.

Ora é neste entrecruzamento entre espaços de informação eletrónica institucionalmente validados e espaços eletrónicos enquanto espaços de publicação e colaboração aberta que o exemplo do Arquivo LdoD pode ser interessante na sua condição de objeto bibliotecável, isto é, suscetível de ser construído como um item numa biblioteca digital. Na medida em que os objetos digitais que contém (fac-símiles autógrafos e edições em livro desses fac-símiles) são eles próprios objetos catalogados na biblioteca e na medida em que o arquivo oferece um conjunto de funcionalidades de colaboração e produção textual semelhantes às que definem as práticas comunicativas na web 2.0, o Arquivo LdoD mostra a tensão entre modularidade e estabilidade documental - que permitem estabilizar os sistemas de coleção, referência e classificação da biblioteca - e a reticularidade e instabilidade documental inerentes à rápida socialização e à crescente temporização dos processos textuais em meio digital.

\section{Instabilidade textual e variabilidade modular}

Quais seriam as possíveis consequências para o conhecimento da história, e de tudo o que nos rodeia, se o conteúdo dos livros pudesse ser continuamente alterado? Esta pergunta é interessante de um ponto 
de vista de uma teoria do conhecimento histórico: num certo sentido, o conhecimento histórico depende da estabilidade dos documentos. Por outro lado, o conhecimento consiste na descoberta de novas relações entre os factos e os processos históricos descritos ou inferidos a partir das evidências materiais e documentais. Ou seja, ainda que os documentos mantenham a sua estabilidade textual, o conhecimento da história obriga a reescrever, sempre com novas aproximações e perspetivas, as narrativas em que surgem os documentos do passado. Ainda que os textos permaneçam fechados na sua estrutura narrativa e na sua forma material, os processos de leitura e os atos de conhecimento estão constantemente a reabri-los.

Sob este ponto de vista, o hipertexto apenas tornaria materialmente visível o processo semântico e hermenêutico de escrever e ler como prática social e cognitiva inscrita na temporalidade que tenta descrever. A alegada volatilidade da produção documental eletrónica resultaria afinal de uma conceção de arquivo e de biblioteca em que à escrita e ao suporte da escrita é atribuído o poder mágico de fixar os significantes fora da temporalidade que os produziu. Esse preciosismo arqueológico ignoraria a dimensão performativa dos atos simbólicos de que os documentos apenas podem constituir vestígios. Ao aproximar a escrita da fala, as tecnologias da informação redefinem a documentabilidade, conferindo-lhe uma espécie de reconfigurabilidade contínua, com a possibilidade de rápida multiplicação de versões e estágios de publicação. O que seria bibliotecar neste contexto: selecionar e classificar determinadas versões desses documentos reconfigurados? Catalogar as variações autodocumentadas nos próprios ficheiros?

Que alteração produz a mediação digital na modularidade documental, institucionalmente estabilizada num conjunto de formas textuais progressivamente reforçadas pelos sistemas classificatórios da biblioteca e do arquivo? Existem já géneros e formas intrinsecamente digitais? Ou apenas formas resultantes da adaptação e transposição de géneros e formas de outros meios? A remediação cria novos géneros ou modifica apenas os géneros anteriores? O sítio web é um género característico do novo meio, como o jornal, por exemplo, se tornou característico da imprensa? Ou é 
apenas uma estrutura de organização suscetível de acomodar géneros e formas muito diferentes, como um códice? Se assim é, haverá propriedades dos programas de hipertexto e das páginas web que tenham consequências poéticas? Se certas propriedades dos textos são intrínsecas aos géneros e formas, isto significaria que mesmo reproduzidas sob a forma de hipertexto haveria uma unidade de escrita e de leitura que os definiria e limitaria de um ponto de vista discursivo e semântico. Neste caso, ainda que pudessem ser um elemento de uma rede hipertextual e lhes fossem acrescentados elementos específicos da transmissão digital, possuiriam ao mesmo tempo a completude, fixidez e funcionalidade de um género tipográfico.

Visto assim, o hipertexto seria mais um arquivo de textos e criações mediais que manteriam as suas propriedades fundamentais, ainda que reconfigurados de forma diferente da de uma biblioteca, ou de uma antologia, ou de um jornal. Por outro lado, podemos perguntar o que significa a infinitude hipertextual? Considerada enquanto rede de textos (isto é, um hipertexto de hipertextos, ou arquivo de arquivos), a infinitude parece caracterizar o ambiente de leitura em linha, na medida em que é sempre possível reassociar documentos. Todavia, continua a haver a possibilidade de publicar os textos respeitando as modularidades (de género, de edição, de desenho gráfico, etc.) característicos da reprodução impressa. Talvez por isso Ted Nelson ${ }^{13}$ afirme que o hipertexto que temos continua a ser uma mera imitação do papel, que materializa as suas convenções de ligação interna e externa como metáforas das conexões bibliográficas. O formato PDF, por exemplo, é geralmente usado com a finalidade de fazer coincidir a unidade ficheiro com a unidade género impresso. Quer dizer que continua a ser possível recriar as unidades discursivas e semânticas características dos textos impressos, uma vez que a estrutura princípio-meio-fim é também uma propriedade do género e da forma e não apenas do suporte material. Ou seja, a continuidade intro-

13 NELSON, Theodor Holm - Transliterature: a humanist format for re-usable documents and media. Oxford Internet Institute and Project Xanadu, 2007. [Consult. 26 mai. 2014]. Disponível na WWW em: <URL:http://transliterature.org>. 
duzida pela inserção do texto numa rede não exclui a descontinuidade da perceção de um todo, ainda que este já não possa ser percecionado como a unidade material discreta que resultaria de um volume impresso e seja antes visto como uma unidade discursiva suscetível de remediações, rematerializações e reassociações.

Por outro lado, é evidente também a ligação das propriedades do meio às propriedades dos géneros, vinculando-os a tecnologias específicas. O desenvolvimento do romance, por exemplo, nos seus inúmeros subgéneros, não se pode separar da tecnologia da imprensa. Que grau de transformação dos géneros e formas anteriores é necessário para que o meio digital seja mais do que uma tecnologia de reprodução e de distribuição, passando a determinar certas propriedades formais e discursivas dos textos? A utilização de dispositivos como a animação, o grafismo digital e a hiperligação são suficientes para produzir um género digital? Por outro lado, a digitalidade dos géneros digitais atuais não será também uma função das aplicações informáticas? Isto é, não haverá propriedades textuais que devam ser ligadas a ferramentas informáticas específicas e não à natureza digital da criação e transmissão? E teríamos de falar da página web Dreamweaver, do poema Flash, do conto StorySpace, do repositório DSpace, do blog WordPress?

Neste caso, certas propriedades textuais, gráficas e funcionais dependeriam de gerações específicas de aplicações e de hardware, tal como aconteceu com as técnicas particulares de produção e encadernação de manuscritos medievais ou com as diferentes inovações nas técnicas e formatos de impressão. Na medida em que tais propriedades modificassem substancialmente as possibilidades combinatórias e estruturais dos elementos que definem um género ou forma, os programas informáticos passam a fazer parte da descrição do género e da forma. Por outro lado ainda, da construção de hipertextos sob a forma de arquivos estruturados de textos ligados a uma obra ou a um autor, por exemplo, não resultará a criação de novos géneros, ou meta-géneros, caracterizados precisamente por uma determinada forma de ligar entre si os ficheiros e produzir uma teia discursiva? Neste caso, a edição eletrónica sob a forma de arquivo digital, ao arquitetar um determinado ciberespaço meta-documental com 
o corpus de um autor estaria também a definir um género ou forma digital específica.

\section{O arquivo digital dinâmico é bibliotecável?}

A edição de obras em meio digital sob a forma de arquivos em construção é um caso em que podemos observar simultaneamente a instabilidade que decorre da reconfiguração contínua do ficheiro de dados, e a produção de modularidades que parecem escapar aos esquemas de metadados herdados da cultura bibliográfica. O exemplo que trago para justificar este conjunto de interrogações é o Arquivo Digital LdoD, dedicado ao Livro do Desassossego de Bernardo Soares/Fernando Pessoa ${ }^{14}$. Neste arquivo podemos observar simultaneamente a presença das modularidades documentais e genéricas anteriores, isto é, a dos fac-símiles dos manuscritos que fazem parte do espólio guardado na Biblioteca Nacional (incluindo a sua remediação sob a forma de fac-símiles digitais a incluir no sítio web 'Espólio Fernando Pessoa' da Biblioteca Nacional Digital) e a dos livros impressos produzidos pelos diferentes editores da obra (Coelho, Cunha, Zenith e Pizarro). Podemos ainda observar a dissolução dessas modularidades numa rede reticular de ficheiros suscetíveis de se modificarem e de se incrementarem com a manipulação e intervenção dos utilizadores, que vão reconfigurando ao longo do tempo os próprios objetos digitais contidos no arquivo ${ }^{15}$. Se pensarmos que o Arquivo LdoD, à semelhança de muitos conteúdos da web 2.0, está concebido para se reconfigurar continuamente pela ação coletiva dos leitores, como poderemos representar a sua identidade documental?

14 PORTElA, Manuel - Nenhum problema tem solução: um arquivo digital do Livro do Desassossego. MatLit. 1:1 (2013) 9-33. [Consult. 26 mai. 2014]. Disponível na WWW em: <URL: http://iduc.uc.pt/index.php/matlit/article/view/1618>.

15 SILVA, António Rito e PORTEla, Manuel - TEI4LdoD: textual encoding and social editing in Web 2.0 environments. Journal of the Text Encoding Initiative. 8 (2014). [no prelo]. 


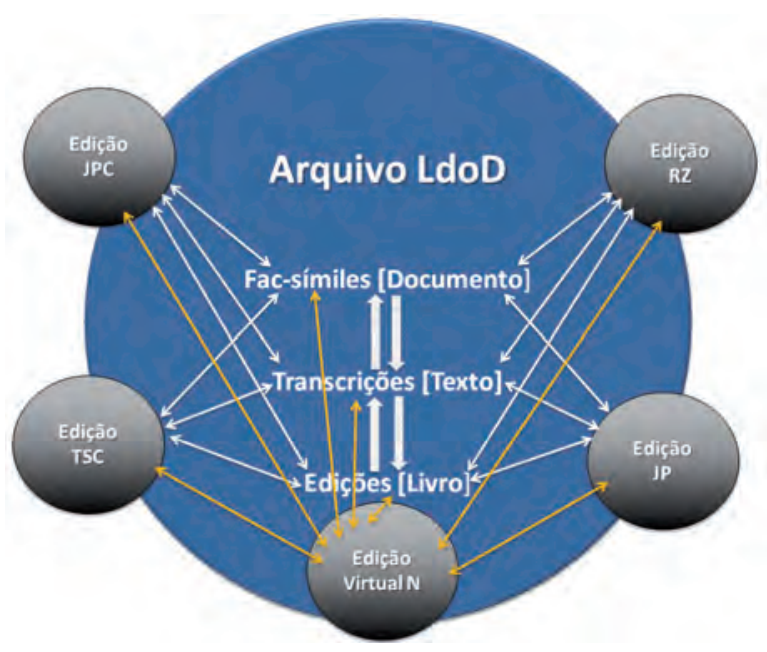

FIGURA 5. Diagrama representando a natureza dinâmica do Arquivo LdoD.

(C) Manuel Portela, 2014.

A Figura 5 representa as diversas camadas e funcionalidades previstas no Arquivo $L d o D$. A camada estática do arquivo contém fac-símiles dos documentos autógrafos, transcrições topográficas desses documentos codificadas em XML de acordo com a norma da Text Encoding Initiative e ainda transcrições textuais correspondentes às quatro edições principais. Estas cinco transcrições podem ser automaticamente comparadas entre si e pesquisadas de acordo com múltiplos critérios. Designadas como edições dos peritos no contexto do arquivo, estas transcrições constituem também a base material para a camada dinâmica que permitirá aos utilizadores classificarem, anotarem, (re)editarem e (re)escreverem - de forma individual ou coletiva - os fragmentos contidos na base de dados ${ }^{16}$. Por seu turno, todas estas intervenções podem ser publicadas e tornar-se elementos permanentes ao nível da camada virtual do arquivo, criando

16 PORTElA, Manuel e SILVA, António Rito - A model for a virtual LdoD. Literary and Linguistic Computing. (2014) [no prelo]. Advanced online publication. 5 March 2014. [Consult. 26 mai. 2014]. Disponível na WWW em: <URL:http://llc.oxfordjournals.org/content/ early/2014/03/05/1lc.fqu004.abstract>. 
um circuito de retroalimentação colaborativa e aberta entre o nível das edições dos peritos e o nível das edições virtuais.

A pergunta que volto a fazer, a partir deste exemplo, é esta: o que seria uma biblioteca digital de arquivos digitais como este? Seria a biblioteca digital um instrumento de produção de ordem na ramificação caótica do hipertexto, capaz de conformar aos campos Dublin Core mesmo os objetos que escapassem à taxonomia bibliográfica? Outra forma de formular a mesma pergunta: o conceito de biblioteca sobreviverá num universo de informação integralmente digital? E se em vez de pensarmos na biblioteca digital como remediação das bibliotecas de papel e das mediatecas ou como coleções de objetos digitais institucionalmente classificados e validados, pensarmos na biblioteca digital como a mera combinação das funções de pesquisa, localização e apresentação da informação e da meta-informação constante dos próprios ficheiros? Isto é, como uma forma de pesquisa estruturada no universo documental da própria internet? Poderá a biblioteca digital vir a ser apenas a conjunção de um sistema de metadados com um conjunto de algoritmos, suportados pela infraestrutura eletrónica que permite as transferências de dados?

O Arquivo LdoD, tal como projetos similares de arquivo digital de obras literárias, mostra a reconfiguração das modularidades documentais que estão na base dos conceitos de edição, arquivo e biblioteca, bem como das relações entre conteúdo e continente. A flexibilidade da representação numérica digital permite que os documentos sejam modularizados de acordo com a materialidade específica do meio digital independentemente da modularidade dos objetos originais. Assim, ao mesmo tempo em que contém um conjunto de edições que corresponderiam a livros impressos ou a documentos singulares autógrafos, o Arquivo LdoD é, ele próprio, suscetível de constituir-se como um item webliográfico ou bibliográfico numa biblioteca digital. Enquanto representação digital, parte da sua função é preservar e tornar acessível o espólio autoral bem como as configurações editoriais da obra ao longo do tempo. O próprio arquivo, enquanto criação concetual e técnica experimental, subordina-se aos protocolos de preservação e classificação da informação digital. Todavia, ao instituir-se como arquivo aberto, suscetível de construção 
pelos utilizadores, o Arquivo $L d o D$ assimila internamente a lógica da própria internet, excedendo, por assim dizer, os campos do catálogo que o descreve.

Um dos efeitos das novas tecnologias, consequência da alteração da escala física dos objetos de informação, que passaram a poder ser representados foto-eletronicamente nos ecrãs e nos circuitos dos nossos dispositivos digitais e a ser distribuídos em rede, parece ser justamente a variabilidade das suas agregações, isto é, o modo como podemos definir as unidades de pesquisa e manipular os objetos correspondentes. O formato de ficheiro enquanto codificação informática específica passou a ser também uma unidade documental para efeitos de classificação, pesquisa e preservação. Um arquivo literário digital constitui, de certo modo, um ecossistema documental onde é possível observar a reconfiguração das relações entre unidades documentais analógicas e unidades documentais digitais, decorrentes das interferências entre categorias classificatórias bibliográficas e as categorias classificatórias informáticas ${ }^{17}$. A unidade entre forma material e forma discursiva que identifica um género passa a poder ser representada digitalmente através de diferentes formatos de ficheiro, dando origem a novas modularidades suscetíveis de cruzamentos, misturas e agregações. Os algoritmos de pesquisa característicos do catálogo bibliográfico podem estender-se e combinar-se com possibilidades associativas e reticulares da web semântica.

É certo que o arquivo literário digital colaborativo é bibliotecável no sentido em que a sua unidade enquanto arquivo é suscetível de ser referida e referenciada como uma unidade, isto é, através de um identificador único, do qual dependeriam hierárquica ou associativamente os restantes elementos. No entanto, a sua natureza dinâmica implica a mudança do conteúdo ao longo do tempo numa reconfiguração parcial dos ficheiros de dados e metadados que o constituem e descrevem enquanto objeto digital, fazendo-o extravasar o enquadramento da biblioteca em função da

17 PORTELA, Manuel - Multimodal editing and archival performance: a diagrammatic essay on transcoding experimental literature. Digital Humanities Quarterly. 8:1 (2014). [Consult. 26 mai. 2014]. Disponível na WWW em: <URL:http://www.digitalhumanities.org/ dhq/vol/8/1/000175/000175.html>. 
lógica proliferativa e socializada dos média digitais em rede. Este constitui talvez o ponto em que a metáfora da biblioteca digital deixaria de ser operacional enquanto meta-representação catalogada de uma coleção de objetos para se redefinir a partir da especificidade abstrata do meio digital como certo tipo de relação entre estruturas de dados e algoritmos.

\section{Referências bibliográficas}

BIBLIOTECA NACIONAL DE PORTUGAL - Biblioteca nacional digital. Lisboa: BNP, 2002. [Consult. 26 Mai. 2014]. Disponível na WWW em: <URL:http://purl.pt/ index/geral/PT/index.html>.

Candela, L. [et al.] - Digital library manifesto. [Em linha]. DL.org Consortium. 2011a. [Consult. 26 Mai. 2014]. Disponível na WWW em: <URL: http://www. dlorg.eu>.

CANDELA, L. [et al.] - Digital library reference model: in a nutshell. [Em linha]. DL.org Consortium. 2011b. [Consult. 26 Mai. 2014]. Disponível na WWW em: <URL:http://www.dlorg.eu>.

Digital PUblic Library OF AMERICA. Boston: Boston Public Library, 2013-2014. [Consult. 26 mai. 2014]. Disponível na WWW em: <URL: http://dp.la>.

INTERNET ARCHIVE. San Francisco: Internet Archive, 1996-2014. [Consult. 26 mai. 2014]. Disponível na WWW em: <URL: https://archive.org/index.php>.

MANOVICH, Lev - Software takes command: extending the language of new media. London: Bloomsbury, 2013.

NAMORA, Ricardo - El concepto de biblioteca digital como cuestión epistemológica. GARRIDO GaLlardo, Miguel Ángel, ed. - La biblioteca de Occidente en contexto hispánico. Logroño: Universidad Internacional de La Rioja, 2013. p. 73-84.

NELSON, Theodor Holm - Transliterature: a humanist format for re-usable documents and media. Oxford Internet Institute and Project Xanadu, 2007. [Consult. 26 mai. 2014]. Disponível na WWW em: <URL:http://transliterature.org>. PESSOA, Fernando - Livro do desassossego. Jacinto do Prado Coelho, org. Lisboa: Ática, 1982. 2 vol.

PESSOA, Fernando - Livro do desassossego. Teresa Sobral Cunha, org. Lisboa: Relógio d’Água, 2008. 
PESSOA, Fernando - Livro do desasocego. Jerónimo Pizarro, org. Lisboa: Imprensa Nacional-Casa da Moeda, 2010. 2 vol.

PESSOA, Fernando - Livro do desassossego. Richard Zenith, org. Lisboa: Assírio \& Alvim, 2012.

PORTELA, Manuel - Nenhum problema tem solução: um arquivo digital do Livro do Desassossego. MatLit. 1:1 (2013) 9-33. [Consult. 26 mai. 2014]. Disponível na WWW em: <URL: http://iduc.uc.pt/index.php/matlit/article/view/1618>.

PORTELA, Manuel - Multimodal editing and archival performance: a diagrammatic essay on transcoding experimental literature. Digital Humanities Quarterly. 8:1 (2014). [Consult. 26 mai. 2014]. Disponível na WWW em: <URL:http://www. digitalhumanities.org/dhq/vol/8/1/000175/000175.html>.

PORTElA, Manuel e SILVA, António Rito - A model for a virtual LdoD. Literary and Linguistic Computing. (2014) [no prelo]. Advanced online publication. 5 March 2014. [Consult. 26 mai. 2014]. Disponível na WWW em: <URL:http://llc. oxfordjournals.org/content/early/2014/03/05/1lc.fqu004.abstract>.

SILVA, António Rito e PORTElA, Manuel - TEI4LdoD: textual encoding and social editing in Web 2.0 environments. Journal of the Text Encoding Initiative. 8 (2014). [no prelo].

THE EUROPEANA FOUNDATION - Europeana. The Hague: National Library of the Netherlands, 2008-2014. [Consult. 26 mai. 2014]. Disponível na WWW em: <URL:http://www.europeana.eu>. 
José Augusto Cardoso Bernardes é Professor da Faculdade de Letras da Universidade de Coimbra e Diretor da Biblioteca Geral da Universidade

Ana Maria Eva Miguéis é coordenadora do Serviço Integrado das Bibliotecas da Universidade de Coimbra

Carla Ferreira é bibliotecária nos Serviços de Biblioteca e Documentação da Faculdade de Letras da Universidade de Coimbra. 


\section{Série Documentos}

Imprensa da Universidade de Coimbra

Coimbra University Press

2015

C •

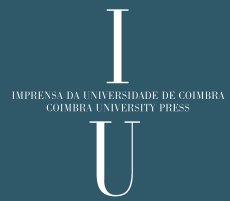

